\title{
Integration of Tobacco Control in Masters of Public Health Curricula of India
}

\author{
Aman Yadav ${ }^{1}$, Sonu Goel ${ }^{2 *}$, Vijay Lakshmi Sharma ${ }^{3}$
}

\begin{abstract}
Context: Tobacco is the single largest cause of preventable death among adults globally, as it is in India. Despite this alarming situation, there is very minimal inclusion of tobacco in formal education systems, including the medical discipline, in India. Aims: The present study analyzed the extent of integration of tobacco control related content in Masters of Public Health (MPH) curricula of various institutes in India. Materials and Methods: This cross-sectional study was conducted during January 2011 to May 2011 in all colleges of the country offering a MPH course. The colleges were enlisted using various internet search engines (Google Scholar,Pubmed, Medline), other published literature and snowball technique. A 50 items semi-structured questionnaire was designed, posted and e-mailed (followed by hard copy) to the Person-In-Charge of the MPH program. Statistical Analysis: Descriptive statistics were used to profile the tobacco control content in respective institutions. All data entry and analysis was conducted using SPSS (version 16) for windows. Results: The duration of the MPH course was two years in all institutes and had accreditation with some affiliated body. Tobacco related diseases were covered under 'non communicable diseases' section by every institute. However, a mere $41.4 \%$ of institute's had faculty who had received specialized training in tobacco control. More coverage was given to health risks and effects of smoking as compared to cessation interventions ( $5 \mathrm{~A}$ 's), symptoms of withdrawal and pharmacological treatments. Only $25 \%$ of institutes were in process of introducing tobacco courses into their curricula. Lack of expertise and administrative barriers were cited as perceived major problems in inclusion of tobacco control in MPH curricula. Conclusions: It can be concluded that tobacco control is not receiving adequate attention in public health curricula in India. There is a need for coordinated efforts in the area of tobacco control so as to reduce morbidity and mortality from tobacco induced diseases.
\end{abstract}

Keywords: Tobacco - tobacco control - curricula - MPH courses - smoking - tobacco related diseases - India

Asian Pac J Cancer Prev, 15 (14), 5611-5615

\section{Introduction}

Tobacco use is the major risk factor for morbidity and mortality in world with around 6 million people becoming victim of tobacco menace each year (Cummings et al., 1987). According to WHO, tobacco will be responsible for 8 million deaths per year by the decade 2030, with $80 \%$ of them occurring in developing countries and around one billion premature deaths during 21st century (Ferry et al., 1999). India has second largest group of smokers in the world with around 120 million smokes some form of tobacco (GTSS Collaborative Group, 2006). In 2010, one million Indians were expected to die from tobacco related causes (International Institute of Population Sciences (IIPS), Macro International, 2007). Global Youth Tobacco Survey (GYTS) and Global School Personnel Survey (GSPS) reported that the current use of any tobacco product was $14.1 \%$ among students (17.3\% boys, $9.8 \%$ girls) and among school personnel it was $29.2 \%$ (35.0\% males and $13.7 \%$ females) (Sinha et al., 2007).
Various studies conducted to measure compliance to prohibition of smoking at public places in India (under section- 4 of cigarettes and other tobacco products act (COTPA) in 2003) have shown mixed results (Goel et al., 2014; Kumar et al., 2014). Another study conducted in a health care institution of India has observed an overall compliance rate to smoke-free provisions of COTPA to be mere 23\% (Tripathy et al., 2013).

Despite this grave scenario, there is very minimal inclusion of tobacco control in formal education system in India. School based programmes focusing on tobacco control in developing nations have successfully demonstrated their impact on knowledge, attitude and tobacco use patterns among students (Jha et al., 2008; Khan et al., 2012). Although few knowledge is provided to students upto 8th standard through a subject called 'Moral Science' but that is hardly sufficient to inculcate strong belief in younger population about menace of tobacco. The Central Board of Secondary Education, as part of the Adolescent Education Program and Comprehensive 
School Health Program, has been constantly endeavoring to raise awareness regarding prevention of students from becoming addicted to tobacco as well as the dangers of exposure to tobacco smoke (Central Board of Secondary Education, 2005).

However, there is lack of professional education in tobacco control in different disciplines. Even in medical colleges, more stress is given to infectious diseases and treatment of pathologies rather than study of risk factors and determinants of diseases. The Srivastava Committee Report in 1975 recommended including public health issues in medical curricula (Srivastava Committee Report, 1975). World Health Organization (WHO) highlighted the role of trained public health professional in tobacco control during "World No Tobacco Day" on May 31, 2005 (World Health Organization, 2005). Tobacco use among health care professionals has been cited to be a major barrier to tobacco control interventions worldwide (Negandhi H et al., 2010).World Health Organization thus recommends the inclusion of tobacco control in all health professional's curricula (Philip et al., 2003). The involvement of public health experts could help in controlling global tobacco use and promoting health, thus their education regarding the multiple aspect of tobacco can prove to be beneficial for the world (Richmond et al., 1998).

Establishment of Preventive and Social Medicine (PSM) departments in medical colleges was a step in the right direction, however, lack of interest in discipline among students, lack of adequate exposure in public health concerns and lack of coordination with other clinical departments has led to its aloofness and decreased importance in the field of medical sciences. Recently, Schools of Public Health have been launched in some medical and non-medical institutes, which can potentially complement and strengthen the activities of the community medicine departments by offering opportunities for Public Health Education (PHE) to both medical and non-medical graduates (Raupach et al., 2009). Masters of Public Health (MPH) is a two year course offered currently by 23 public health institutions of India. It has a right mix of various public health disciplines like epidemiology of communicable and non communicable diseases, health management, health promotion, health economics, primary health care, social sciences, women's health, child health, research methodology etc (Raupach et al., 2009).

The present study analyzed the extent of integration of tobacco control related content in MPH curricula of various institutes in India.

\section{Materials and Methods}

The study used a cross sectional design in which all colleges of country offering Masters of Public Health course were enlisted using various internet search engines like google scholar, Pubmed, Medline, and other published literature. Besides this, snowball technique was used to search for an additional school across country. Study was conducted during January 2011 to May 2011.

A 50 items semi structured questionnaire was designed, posted and e-mailed (followed by hard copy) to the InCharge of MPH program. The reliability and validity of questionnaire was tested by "test retest" method. It contained questions on the following topics: infrastructure of department, faculty strength, extent of coverage of tobacco cessation intervention, methods used for teaching tobacco, opinion about inclusion of more tobacco content in curricula etc. They were requested to reply back in 7 days. Three reminders were sent each after duration of one week to the respondents. One contact was also made telephonically to request for the details.

Descriptive statistics were used to profile the tobacco control content in respective institutions. All data entry and analysis was conducted using SPSS (version 16) for windows.

\section{Results}

The number of institutions offering MPH course in India at time of survey is shown in Table1. Different institutes had separate criteria to enroll students in MPH programme. The duration of MPH course was two years in all institutes and had accreditation with some affiliated body.

Tobacco related diseases were covered under non communicable diseases section by every institute but basics about tobacco control was not covered by any institute. $41.4 \%$ of institute's had faculty which got specialized training in tobacco. None of the institute reportedly provided any separate credits in tobacco.

As shown in Table 2 majority of topics related to health hazards of tobacco were covered in public health curricula as part of required courses. Health effects of tobacco and diseases caused by tobacco were taught in $83 \%$ institutes.

Table 1. MPH Programs in Survey Institutions of India

\begin{tabular}{|l|l|l|}
\hline Institutions & Eligibility criteria & Accrediting body \\
\hline Tata Institute of Social Sciences & M.B.B.S, B.D.S, M.Sc or their equivalent & TISS \\
Jawaharlal Nehru University & M.B.B.S and M.Sc (Nursing) & Jawaharlal Nehru University \\
Panjab University & Any Graduate with 50\% marks & Panjab University \\
Asian Institute of Public Health & Bachelor's degree in medical and paramedical sciences & Ravenshaw University \\
Interdisciplinary School of Public Health & Bachelor's degree in medical and paramedical sciences & University of Pune \\
Eternal University & 12th pass students can apply for MPH as integrated course & Eternal University \\
Jodhpur School of Public Health & Bachelor's degree in medical and paramedical sciences & Jodhpur National University \\
BITS, Pilani & Bachelor's degree in medical and paramedical sciences & BITS \\
School of Public Health, PGIMER & MBBS, BDS, BVSc, MA, MSc & PGIMER \\
San Hoggins institute of Agriculture and Technology & Any Graduate with 50\% marks & SHIAT University \\
National institute of Mental Health and Neurosciences & MBBS, BDS, BVSc, MA, MSc & NIMHS \\
CMC, Vellore & MBBS, BDS, BVSc, MA, MSc & CMC \\
\hline
\end{tabular}

*All were full time course 
Practices, prevalence, patterns of tobacco use in India were covered by only $42 \%$ institutes. Global tobacco control policies and policies adopted by India to curb the menace were merely covered by $33 \%$ and $50 \%$ institutes respectively. In all the school surveyed, greater coverage was given to health risks and effects of smoking and less to content on cessation intervention (5 A's), symptom of withdrawal and pharmacological treatments (Table 2).

$83.3 \%$ of teachers reported that audio visual and workshop were the most preferred method of introducing tobacco in curriculum. Role play $(33.3 \%)$ was the least preferred method in teaching (Figure 1).

Only $25 \%$ institute were in process of introducing tobacco course in their curricula while all other responding institutes were willing to introduce tobacco course as separate module/credits in MPH degree.

Table 4 shows the barrier in including tobacco in MPH curricula. Lack of expertise and administrative barrier was cited as perceived major barrier in inclusion of tobacco in MPH curricula (Table 3 ).

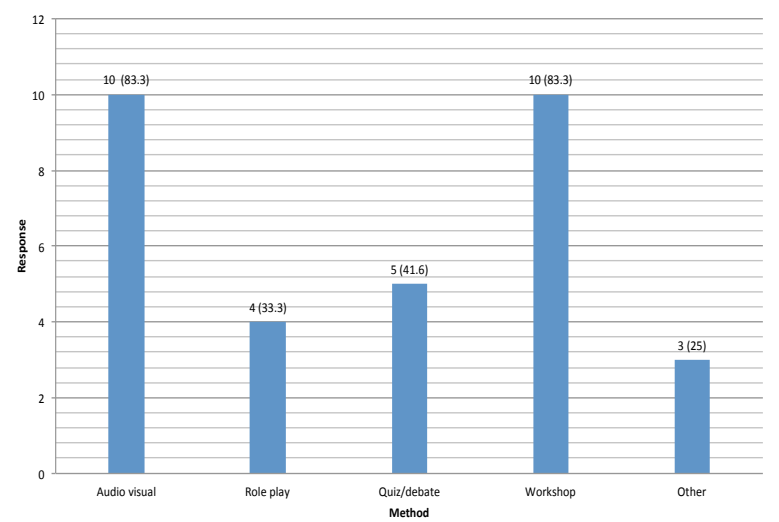

Figure 1. Teachers' Perception about Most Preferred Method of Introducing Tobacco in Curriculum

Table 2. Topics Included in Tobacco-Related Education within the Public Health Curriculum

\begin{tabular}{lc}
\hline Areas & $\mathrm{N}=12 \mathrm{n} *(\%)$ \\
\hline History of tobacco use & $5(42)$ \\
Practices, prevalence, patterns in India & $5(42)$ \\
Health effects & $10(83)$ \\
Environmental effects & $11(92)$ \\
Global control policies & $4(33)$ \\
Policies in India & $6(50)$ \\
Surveys in India & $5(42)$ \\
Second hand smoke & $8(67)$ \\
Pharmacological agents & $3(25)$ \\
Knowledge about 5 A's & $3(25)$ \\
Tobacco related diseases & $11(92)$ \\
Economics of tobacco control & $8(67)$ \\
\hline *Denotes yes &
\end{tabular}

Table 3. Perceived Barriers of Including Tobacco Control in MPH Curricula

\begin{tabular}{lc}
\hline Barrier & Respondents in agreement $(\%)$ \\
\hline Faculty resistance & $1(8.3)$ \\
Students resistance & 0 \\
Administrative resistance & $5(41.6)$ \\
Lack of expertise & $5(41.6)$ \\
\hline
\end{tabular}

\section{Discussion}

With the passage of time, there is an ever increasing burden of both communicable and non-communicable diseases in developing countries. As tobacco is emerging as major threat for non- communicable diseases, it is important for public professionals to concentrate on new emerging health issues like tobacco control. It is our strong opinion that the emergence of newer discipline of Masters in Public Health (MPH) in India can also be looked as an opportunity to train these young and diverse professionals in tobacco control. Negandhi et al. (2010) in their paper had concluded that the departments of community medicine can ideally offer a skill and competency-based curriculum, integrating the disease pathology, the casemanagement and disease prevention/ control and skill to curb new epidemics like tobacco (Negandhi et al., 2010).

Integration of tobacco content in core courses of Masters of Public Health program will improve knowledge of tobacco, control and prevention among MPH students. We observed in our study that only $25 \%$ institutes incorporated 5 A's of tobacco cessation in their curricula. Tobias Raupach et al. (2009) in their study on knowledge of students of two European medical colleges about tobacco showed that medical students lacked basic knowledge about smoking cessation and teaching of smoking cessation methods was not a top priority in their medical curricula (Raupach et al., 2009). Stillman et al. (2006) in their study had also cited that significant proportion of public health students in the U.S. received only a modest introduction to tobacco, while only a very small fraction receive substantial, in-depth training in tobacco control strategies (Stillman et al., 2005; Stillman et al., 2006). Oberoi et al. (2014) has recommended that there should be certified courses on tobacco cessation and these courses of short-term duration can be developed to provide basic knowledge of tobacco cessation including the pharmacotherapy (Oberoi et al., 2014). The effectiveness of tobacco use cessation (TUC) counseling in dental office has also been demonstrated in a study by Halawany et al. (2013) in which more smokers agreed to counselling as compared to non-smokers (Halawany et al., 2013).

The present study found that all participating institutes cover tobacco related diseases, but there was no specific module on tobacco control. Discussion of tobacco was done under non communicable disease topic only. The most popular teaching method was lectures and presentations. These results were similar to the study done by Richmond Robyn et al. (1998) where most medical schools addressed the issues of tobacco and related diseases at some level (Richmond et al., 1998). Only $11 \%$ of respondents indicated the presence of a specific teaching module for tobacco issues. The most popular teaching formats were lectures (91\%). Ferry et al. (1999) revealed that out of 126 medical colleges, only 3 schools $(2.4 \%)$ had a devoted course for tobacco education (Ferry et al., 1999). Philip et al. (2003) has also concluded that comprehensive school based tobacco control project significantly reduced the tobacco use pattern in the target population (Philip et al., 2003). 
In the present study, students were examined on their knowledge of tobacco and related diseases in their courses. The main content of MPH curricula were directed to impart knowledge of major tobacco-related diseases (96\%), to raise public awareness about the dangers of smoking and its impact on health $(76 \%)$, and to give the students an understanding of the physical and psychological effects of nicotine addiction (73\%). The smoking cessation techniques (34\%) were least informed. Sailesh et al (2006) in their study reported that most (87\%) institutions desired to receive lectures on tobacco control as part of subjects such as community medicine, internal medicine and respiratory medicine. Binnal et al (2012) has also reported that the mean knowledge score of dental professionals on tobacco control was $73.3 \%$ and $97 \%$ were willing to participate in tobacco control activities (Binnal et al., 2012).

Our study revealed that only $41.6 \%$ MPH institutes had faculty specialized in field of tobacco control. Scarcity of faculty in field of tobacco acts as barrier in controlling this epidemic. The results of our study were similar to study conducted by Sinha et al. (2007) where $84 \%$ of teachers lacked training in tobacco related aspects (Sinha et al., 2007). This also indicates the extent of undermining the scope of tobacco control in public health schools across country. A study by Parakh et al. (2013) conducted among dental practitioners of Chhattisgarh, India has concluded that although all dentists wanted TCC training to be a part of practice and that it should be included in dental curriculum, however, few of them considered that it might have a negative impact on their clinical practice (17\%), take away precious time from their practice (24\%), and might not be effective due to lack of formal training (80\%) (Parakh et al., 2013). 41.6\% institutes in our study have admitted resistance from administration to include more tobacco content in curriculum. Ferry et al. (1999) had cited that the perception of administration and medical fraternity towards communicable diseases, and lack of infrastructure were barriers to introducing tobacco control in curricula (Ferry et al., 1999).

The study results are based on knowledge and perceptions of students $\&$ teachers which may not reflect the true picture of the respective institutes and thus may not be representative of general opinion of MPH students and teachers of country. The response rates of institutions are low $(54.4 \%)$.

To ensure that the next generation of public health professionals is well versed in tobacco control, Schools of Public Health must become more active in providing tobacco control training and educational opportunities. Whether the goal is to integrate tobacco control into existing schools of public health curriculum or to design a separate course on tobacco control depends on the capacity of institution. At least one to two faculty of each institution should be extensively trained on tobacco control, so that he/she may act as a champion in area of tobacco control. The students should be oriented in tobacco control especially in areas like 5 A's, pharmacological agents, history of tobacco control and tobacco legislation, which are weak in current curricula. The skills like smoking cessation techniques should be integral part of
MPH curricula. The conferences, seminars, workshops, symposium should be organized by public health institutes in area of tobacco control.

In conclusion, it can be concluded that tobacco control is not receiving adequate attention in public health curricula of country. This deficit may be the result of lack of expertise and training among faculty, insufficient existing curriculum materials and/or absence of leadership and focus among academicians in tobacco control related issues. Our findings support the need for coordinated effort in area of tobacco control so as to reduce morbidity and mortality from tobacco induced diseases.

\section{Acknowledgements}

The authors would like to thank Prof. dr. Karel Geboes, Prof. dr. Wim Ceelen.

\section{References}

Binnal A, Rajesh G, Denny C, Ahmed J (2012). Insights into the tobacco cessation scenario among dental graduates: An Indian perspective. Asian Pac J Cancer Prev, 13, 2611-7.

Cummings KM, Giovino G, Sciandra R, et al (1987). Physician advice to quit smoking: who gets it and who doesn't. Am J Prev Med, 3, 69-75.

Central Board of Secondary Education (2005). National Adolescence Education Programme. Ministry of Human Resource Development, Govt. of India 2005.

Ferry LH, Grissino LM, Runfola PS (1999). Tobacco dependence curricula in US undergraduate medical education. JAMA, 282, 825-9.

Goel S, Ravindra K, Singh RJ, Sharma D (2014). Effective smoke-free policies in achieving a high level of compliance with smoke-free law: experiences from a district of North India. Tob Control, 23, 291-4.

GTSS Collaborative Group (2006). Tobacco use and cessation counselling: Global Health Professionals Survey Pilot Study, 10 countries, 2005. Tob Control, 15, 31-4.

Halawany HS, Jacob V, Abraham NB, Al- Maflehi N (2013). Oral cancer awareness and perception of tobacco use cessation counseling among dental students in four Asian countries. Asian Pac J Cancer Prev, 14, 3619-23.

Health services and medical education: A programme for immediate action, (Srivastava Committee Report, 1975); Ministry of Health and Family Planning. Govt. of India 1975.

International Institute of Population Sciences (IIPS), Macro International (2007). National Family Health Survey (NFHS3), 2005-06: India:1-2. Mumbai IIPS; 2007.

Jha P, Jacob B, Gajalakshmi V, et al (2008). A nationally representative case-control study of smoking and death in India. $N$ Engl J Med, 358, 1137-47.

Khan AA, Dey S, Taha AH, et al (2012). Attitudes of Cairo University medical students toward smoking: the need for tobacco control programs in medical education. J Egypt Public Health Assoc, 87, 1-7.

Kumar R, Goel S, Harries AD, et al (2014). How good is compliance with smoke-free legislation in India? Results of 38 subnational surveys. Int Health, [Epub ahead of print].

Negandhi H, Sharma K, Zodpey SP (2010). How can departments of community medicine shape the future of public health education in India? Indian J Public Health, 54, 184-9.

Oberoi SS, Sharma G, Nagpal A, Oberoi A (2014). Tobacco cessation in India: how can oral health professionals contribute? Asian Pac J Cancer Prev, 15, 2383-91. 
Philip PM, Parambil NA, Bhaskarapillai B, Balasubramanian S (2013). Evaluation of a specially designed tobacco control program to reduce tobacco use among school children in Kerala. Asian Pac J Cancer Prev, 14, 3455-9.

Parakh A, Megalamanegowdru J, Agrawal R, et al (2013). Dental practitioners self reported performance of tobacco cessation counseling interventions: a cross sectional study. Asian Pac J Cancer Prev, 14, 6141-5.

Richmond RL, Debono DS, Larcos D, Kehoe L (1998). Worldwide survey of education on tobacco in medical schools. Tob Control, 7, 247-52.

Raupach T, Shaha L, Baetzing S, et al (2009). Medical students lack basic knowledge about smoking: Findings from two European medical schools. Nicotine Tob Res, 11, 92-8.

Stillman FA, Wipfli HL, Lando HA, Leischow S, Samet JM (2005). Building capacity for international tobacco control research: The Global Tobacco Research Network. Am J Public Health, 95, 965-8.

Stillman F, Wipfli H, Samet J (2006). Reaching and educating the global tobacco control community: innovative approaches to tobacco control training. Public Health Rep, 121, 521-8.

Smith D, Leggat P (2007). An international review of tobacco smoking among medical students. J Postgrad Med, 53, 55-62.

Sinha DN, Gupta PC, Dobe M, Prasad VM (2007). Tobacco control in schools of India: review from India Global School Personnel Survey 2006. Indian J Public Health, 51, 101-6.

Sharma K, Zodpey S (2011). Public health education in India: Need and demand paradox. Indian J Community Med, 36, 178-81.

Sinha DN, Gupta PC, Gangadharan P(2007). Tobacco use among students and school personnel in India. Asian Pac J Cancer Prev, 8, 417-21.

Tripathy JP, Goel S, Patro BK (2013). Compliance monitoring of prohibition of smoking (under section-4 of COTPA) at a tertiary health-care institution in a smoke-free city of India. Lung India, 30, 312-5.

WHO (2005). Role of health professionals in tobacco control. World No Tobaccco Day 2005.

World Health Organization (2011). WHO report on global tobacco pandemic 2011. Geneva World Health Organization 2011.

WHO (2013). Global health risks: mortality and burden of disease attributable to selected major risks. 